\title{
Human Disease and Drug Pharmacology, Complex as Real Life
}

\author{
E. Viayna, I. Sola, O. Di Pietro and D. Muñoz-Torrero*
}

Laboratori de Química Farmacèutica (Unitat Associada al CSIC), Facultat de Farmàcia, and Institut de Biomedicina (IBUB), Universitat de Barcelona, Av. Diagonal 643, E08028-Barcelona, Spain

* Address correspondence to this author at the Laboratori de Química Farmacèutica, Facultat de Farmàcia, Universitat de Barcelona, Av. Diagonal 643, E-08028-Barcelona, Spain; Phone +34-93-4024533; Fax +34-93-4035941; E-mail: dmunoztorrero@ub.edu 
Abstract: In the past decades drug discovery practice has escaped from the complexity of the formerly used phenotypic screening in animals to focus on assessing drug effects on isolated protein targets in the search for drugs that exclusively and potently hit one selected target, thought to be critical for a given disease, while not affecting at all any other target to avoid the occurrence of side-effects. However, reality does not conform to these expectations, and, conversely, this approach has been concurrent with increased attrition figures in late-stage clinical trials, precisely due to lack of efficacy and safety. In this context, a network biology perspective of human disease and treatment has burst into the drug discovery scenario to bring it back to the consideration of the complexity of living organisms and particularly of the (patho)physiological environment where protein targets are (mal)functioning and where drugs have to exert their restoring action. Under this perspective, it has been found that usually there is not one but several disease-causing genes and, therefore, not one but several relevant protein targets to be hit, which do not work on isolation but in a highly interconnected manner, and that most known drugs are inherently promiscuous. In this light, the rationale behind the currently prevailing single-target-based drug discovery approach might even seem a Utopia, while, conversely, the notion that the complexity of human disease must be tackled with complex polypharmacological therapeutic interventions constitutes a difficult-to-refuse argument that is spurring the development of multitarget therapies.

Keywords: Network pharmacology, Polypharmacology, Multitarget therapies, Protein interaction networks, Multitarget drugs. 


\section{INTRODUCTION}

Two important issues in drug discovery programs are the intended pharmacological profile of drugs to be developed and the way their pharmacological profiling is carried out. Several decades ago, drug candidates were subjected to phenotypic pharmacological profiling in animal models to determine their efficacy and safety under the complex physiological or pathophysiological conditions, without paying much attention to the key molecular details of the interaction (affinity / selectivity) of the drug molecule with its potential protein targets. Indeed, physiological responses to drugs were monitored with minimal assumptions regarding the participation of specific molecular targets and/or signaling pathways [1]. Moreover, because the results of these in vivo studies were the consequence of a number of complex pharmacokinetic and pharmacodynamic processes, they were rather difficult to be interpreted thereby rendering it difficult any attempt to establish structure-activity relationships for increasing affinity and/or selectivity for any putative biological target.

Recent advances in molecular and structural biology technologies that allowed isolation and characterization at the atomic level of protein targets and protein target-drug interactions [2] as well as the assumption that a particular disease is caused by an abnormality in one disease-causing gene and in the protein it encodes, has prompted a search for simplicity in drug discovery programs in the last three decades: now drugs effects are studied in a simpler scenario as the pharmacological profiling of drugs is carried out in vitro on isolated protein targets, thus disregarding the (patho)physiological environment of the latter. Thus, the one-disease, one-gene, oneprotein, one-drug philosophy constitutes the rational basis of the so-called reductionist approach of drug discovery, which is the most prevailing paradigm of current rational drug design both in pharmaceutical companies and in academy [3]. In the early steps of 
the drug discovery process the pharmacological profile of new investigational compounds is established by subjecting them to a number of in vitro tests against the particular isolated protein target, considered critical for the disease, that is expected to be hit by the studied compounds, and a number of other isolated related targets that are expected not to be hit by those compounds $[3,4]$.

Regarding the intended pharmacological profile of drugs, now affinity and selectivity of drugs toward protein targets do matter. Working on isolated targets, the structural determinants of the interaction of a drug with the studied molecular targets can be readily dissected, thereby making it feasible the optimization of affinity and selectivity toward the desired target. The final aim of this reductionist approach is obtaining highly potent and exquisitely selective drugs that are only active against the critical protein target to be hit for treating a particular disease while remaining inactive against any other target, whose modulation is thought to inexorably lead to the occurrence of unwanted side-effects [5], thereby fulfilling the philosophy of Paul Ehrlich about "magic bullets" [6] and leading to safer and more effective drugs. With these premises, interaction of a compound with several protein targets, i.e. polypharmacology, has traditionally been perceived negatively, as an undesirable property, inasmuch as it has been thought to be necessarily accompanied by toxicity [7], and those compounds that hit multiple targets are labeled with the pejorative terms of "promiscuous drugs" or "dirty drugs".

In this context, drug discovery programs were expected to be fuelled by the discovery of new disease-causing genes and their encoded proteins to be targeted by drugs. Thus, deep mining of the human genome was expected to provide drug discovery pipelines with a huge number of potential novel drug targets $[1,8]$, thereby increasing the drug 
target space, and the potential for development of innovative drugs, and expanding the opportunities for increased pharmaceutical productivity and revenues.

Indeed, 480 new targets for small molecule drugs have been estimated yet to be mined from the human genome [8], whereas currently known drugs are estimated to hit 500 different molecular targets [3,9]. However, the increase in novel drug targets has been relatively slow after sequenciation of the human genome $[10,11]$.

Not only has the target-based reductionist approach not benefited from a significant increase in the number of novel targets but also its impact on the number of new approved drugs and on the emergence of efficacious and safe treatments has not fulfilled the expectations. Indeed, overall pharmaceutical productivity, as estimated by the rate of drug launches, has been falling since the 1970s [12], and in the past decade target-based drug discovery approaches have led to a significantly lower discovery rate of FDA-approved first-in-class new molecular entities than programs based on phenotypic screening [13]. Overall, concurrent with the prevailing notion that exquisitely selective drugs should be developed, the approval rate for new drugs has been declining despite the huge increase of global investment in drug discovery and development by pharmaceutical industry [14-18]. Lack of efficacy and toxicity account for $60 \%$ of failures during the clinical testing of novel drug candidates, they representing the two main causes of clinical attrition in late-stage drug development [19]. Particularly, the lack of efficacy of many promising drug candidates that have failed in late-stage clinical trials has been ascribed either to the impossibility of finding a single critical molecular target to efficaciously tackle complex diseases [14], or to the selection of a target that resulted not to be critical for the pathophysiology of the disease [20], or to an inappropriate choice of in vitro cellular models for predicting off-target effects [18]. 
As a consequence, after having followed the reductionist approach for nearly three decades, efficacious treatments for many highly prevalent diseases still remain elusive [21], which puts considerable pressure on healthcare systems [8].

The decrease in complexity when shifting from drug discovery approaches based on phenotypic screening to the isolated single protein target-based reductionist approach has also led to a decrease in relevance to the human condition [22], because proteins rarely function in isolation under (patho)physiological conditions but they do interact with other proteins, operating as part of highly interconnected cellular networks $[11,23,24]$.

The notion that drug targets do not have to be considered in isolation but that they should be taken back to their complex physiological context is increasingly gaining adepts. Indeed, protein targets which are critical for a disease and exhibit one-to-one genotype-pathological phenotype mapping seem to be rare, and diseases are rather caused by the dysfunction of a dynamic network of interacting proteins [3]. Consequently, a new paradigm of drug discovery is emerging, the so-called network pharmacology, which considers both the complexity of disease states and also protein targets and drug-target interactions at the molecular level with the final aim of deriving polypharmacological therapies capable of targeting disease-associated network states by simultaneously interacting with multiple relevant targets of a complex disease network rather than individual protein targets alone [19].

\section{THE COMPLEX ENVIRONMENT OF DRUG TARGETS}

Proteins, in general, and drug target proteins in particular, are not alone in the physiological context but they are rather "social" molecules [25]. Proteins and other endogenous macromolecules are inside cells in a very high concentration, physically 
occupying up to a $40 \%$ of the total volume [26]. Under the resulting "macromolecular crowding" many cellular processes that result in increased available volume inside the cell, such as protein folding, protein aggregation and also protein interactions, are stimulated [26-28]. In this light, it can be easily inferred that proteins are prone to associate and interact within biological systems. Indeed, in living organisms proteins as well as other basic macromolecules such as nucleic acids are interconnected, forming a complex network of interactions that allows a continuous flux of information necessary for most cellular functions and eventually for their viability and functionality $[17,23]$. Changes that distort the equilibrium of this physiological network lead to a new network, the pathological network $[5,19,23,29-31]$. The interactions between proteins and other cellular components, rather than the individual proteins, are the real determinants of the behavior of the (patho)physiological system [32]. Thus, diseases should be regarded as disturbed interaction networks rather than alterations of a single “critical" molecular component [17].

Both physiological and pathological networks seem to be stable and robust, as they are resilient to attacks and perturbations. The robustness of biological systems has been clearly demonstrated in large-scale functional genomics studies, where single-gene knock-out experiments in a variety of model organisms have been found to have only little or no effect at all on their phenotypes [19]. Different mechanisms seem to account for the robustness of biological systems, particularly the existence of alternative or failsafe mechanisms where similar (redundancy) or different (diversity) components and modules of the network with overlapping functions can replace some particular components that are failing $[33,34]$. Thus, selective inhibition of an individual protein target of a pathological network by a drug might lead to the activation of multiple redundant or alternative pathways, thereby bypassing the inhibitory effect of the drug 
and resulting in clinical relapse [23,33,35-37]. Conversely, modulation of multiple nodes within a biological network would be rather required to achieve any phenotypic modification [5].

Consideration of diseases as complex inherently robust protein interaction networks that might be vulnerable through modulation at sensitive nodes [23] has immediate implications for drug discovery. As diseases are complex, they require complex therapeutic approaches that should target not single proteins but imbalances of multiple proteins within an interaction network [5,17,19,20,29,30,34,38,39]. In this light, it becomes apparent that exquisitely selective drugs designed as "magic bullets" in the frame of the reductionist approach might easily exhibit lower-than-needed efficacy, which might in a great part account for the high attrition figures in clinical trials during the past decades. On the contrary, network pharmacology involving polypharmacological therapeutic interventions that selectively hit multiple relevant protein targets within the pathological network as "magic shotguns", emerges as a realistic alternative drug discovery approach that should derive treatments with greater clinical efficacy $[4,5,7,17,19,29,39-44]$.

Not only may multiple-target therapeutic interventions afford greater efficacy but they may also lead to increased safety. Because most components of biological networks seem to be weakly and transiently linked with each other, a therapeutic intervention intended to simultaneously modulate multiple points of a pathological network will likely not require a high potency but a low-affinity interaction at each single target [29], so that drug doses can be reduced thereby circumventing or minimizing the occurrence of dose-related side-effects [39]. Moreover, low potency modulation of several targets of the network will likely not trigger large homeostatic processes associated with the appearance of side-effects, which, conversely, can be promoted by highly target-specific 
drugs [45]. Besides, it has been even suggested that partial inhibition of several targets can be not only safer but also more efficient than complete inhibition of a single target [29]

Selection of the multiple points to be hit within a pathological network for an optimal therapeutic intervention requires the knowledge of its detailed protein interaction map. Construction of protein interaction networks usually involves an iterative integration of experimental and computational methodologies [38,46-48]. A first draft of the interactome network can be built on the basis of literature data, by collecting information about the molecular components of the network and the relationships among them. Then, the components and structure of the model are refined by subjecting its molecular components to large-scale genetically-, biologically- and/or chemicallyinduced perturbations and observing the experimental responses (monitoring of gene translation, protein expression, and signaling events, identification of interactions patterns, etc.) to such perturbations. Alternatively, these costly and time- and effortconsuming large scale genomics, proteomics and metabolomics experimental methodologies can be replaced by computational methods that have been developed for predicting protein-protein interactions and constructing interactome models [49-53]. Finally, once a stable network model of a given disease is available, analysis of the topological and dynamic properties of the pathological network will shed light on the molecular mechanisms underlying the pathological process and will allow us to identify some potential biomarkers as well as the optimal combination of targets to be hit by the therapeutic intervention for achieving a maximal modulation of the disease while avoiding redundancies that might neutralize the effects of such intervention [32] and minimizing the appearance of side-effects $[19,38,54]$. Worthy of note, not only should the network positioning of nodes be considered in the selection of the combination of 
protein targets to be hit, but also their druggability is an essential issue. Indeed, it has been estimated that only $10-15 \%$ of the protein components of disease-associated protein interaction networks are amenable for being targeted by small molecule drugs [19].

Advances in high throughput screening and "omics" methodologies, particularly genomics, transcriptomics, proteomics and metabolomics, are allowing us to unveil a great number of protein interactions in a number of model organisms [40,55-60]. Important endeavors are also being done for charting the human protein-protein interaction network [61-63], even taking into account the 3D structures of the interaction partners (3D interactome networks) [25], as well as the interactome networks of human diseases (Fig. 1) [32,63-67], although there is still much to be done [68].

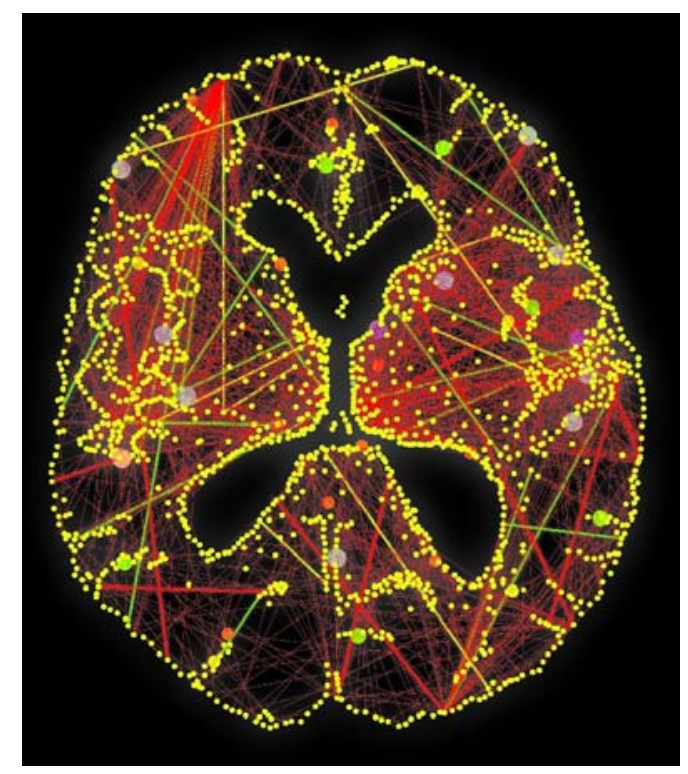

Fig. (1). Artistic representation of the protein interaction network underlying alzheimer's disease [64]. Image created by Dr. Roberto Mosca (IRB, Barcelona). 


\section{COMPLEXITY OF DRUGS, DRUG TARGETS AND DISEASE-CAUSING GENES RELATIONSHIPS}

Consideration that human diseases are caused from an abnormality in a single gene, selection of a given protein target which is critical for a particular disease, and design of drugs that hit that protein target with high affinity and selectivity under the frame of the currently prevailing reductionist drug discovery paradigm not only may fall short of deriving efficacious and safe treatments but these notions themselves are overly simplistic and not accurate.

On the one hand, human diseases are increasingly being found to have several causative factors, and even several genetic diseases that were assumed to be caused by mutations on a single gene have resulted to involve several causative genes. Moreover, the multiple disease-causing genes of many diseases seem to work together in the same biological module or pathway, their encoded proteins having an increased tendency to interact between them, thereby supporting again the conception of diseases as pathological networks [32,69].

On the other hand, it has been found that a particular protein target can be hit by a number of drugs with different chemical structures and even with different therapeutic indications $[11,70]$, a fact that can be understood taking into account that protein targets are often involved in multiple diseases [4].

Finally, many known drugs have been retrospectively found to be able to hit multiple biological targets, even if they were designed to be selective against a particular target $[5,19,71,72]$. Indeed, the presence of polypharmacological profiles in known drugs seems to be the rule rather than the exception $[3,11,45]$. Overall, it has clearly emerged a much more complex picture of the relationships among drugs, protein drug targets and disease-causing genes than initially thought. 
Pretensions to develop target-specific drugs may seem counterintuitive if it is taken into account that: i) the site of action of drugs in the organism is very complex, with many potential interaction partners (proteins, nucleic acids, carbohydrates, metabolites, etc.) and ii) the fact that most drugs are relatively small molecules, and therefore they might be reasonably expected to interact with more or less affinity with more than one intended molecular target among the high number of potential endogenous molecules they may find in the way to their site of action. Recent analysis of drugs-drug targets interactions has suggested that on average each drug interacts with 6 known molecular targets $[73,74]$. A serendipitous match of appropriate biological targets and affinities toward these targets of a successful known drug might account for its clinical efficacy, whereas a mismatch of some of the targets hit by the drug and/or the potency at which they are hit might be responsible for the lower efficacy of other drugs or the lack of efficacy and safety of many recent drug candidates that failed in clinical trials. Interaction of a drug with unexpected molecular targets may certainly lead to undesired side-effects but, very interestingly, also to a higher clinical efficacy [45]. Indeed, the apparent multitarget profile, and therefore promiscuity, of known drugs, seems to directly account for the clinical efficacy of many drugs, notably in therapeutic areas such as cancer and central nervous system diseases [5,39,40,45,75-78]. It has been suggested that drugs of the same therapeutic class and similar clinical efficacy might share a similar pattern of multitarget effects. The study of the drug-drug targets interaction network within a class of drugs might be very useful for unraveling unforeseen important components of their therapeutic mechanism [72] and for charting the coverage maps including the protein targets shared by all the members of the class, which in principle should be considered as responsible for their clinical efficacy [45]. These coverage maps might be used as templates for further optimization of multitarget 
therapeutic interventions, but always keeping in mind the possibility of "false positives" (protein targets shared by all drugs of the class and not linked to clinical efficacy but to side-effects) or "false negatives" (targets non shared by all of the drugs of the class but relevant for individual differences in clinical efficacy) [45].

Some prominent examples of well-known efficacious drugs whose retrospectively established multitarget profile seems to be responsible for their clinical efficacy are briefly discussed below.

Imatinib $\left(\right.$ Gleevec $\left.^{\circledR}\right)$, the first anti-cancer kinase inhibitor to be marketed, was purposely designed and regarded as a paradigm of "magic bullet", i.e. as an exquisitely selective drug that was expected to act on a single aberrant protein expressed in tumor cells, namely the activated p210BCR-ABL tyrosine kinase [79], for specifically killing tumor cells without harming healthy cells. However, soon thereafter it was found that imatinib is not at all as selective as initially thought as it could also interact with other protein targets such as the platelet-derived growth factor receptor (PDGF-R) and c-kit [80,81], among other kinases [82], its multikinase inhibitor profile directly accounting for its outstanding clinical efficacy $[77,80,83]$. These results prompted the development of other compounds with multikinase inhibitor profile and several of them are being already successfully used in the clinics, namely sunitinib, dasatinib, erlotinib, gefitinib, lapatinib, and sorafenib, whereas many others are undergoing clinical testing. Not only have these drugs higher clinical efficacy than classical cytotoxic chemotherapeutic drugs, but they also exhibit a better safety profile [84]. As a class, these anti-cancer kinase inhibitor drugs seem to have quite different profile regarding both the number and the type of the different kinases they target, with some of them being considered more promiscuous (for example, imatinib, sorafenib and sunitinib) than others (for example, erlotinib and gefitinib) [84]. Recently, Karaman et al. have carried out the 
most comprehensive study of kinase inhibitor selectivity to date by testing a set of 38 kinase inhibitors on a panel of 317 kinases, which represent more than $50 \%$ of the predicted human kinome [82]. This study confirmed that kinase inhibitors do clearly have propensity to display a multitarget profile and that currently marketed anti-cancer kinase inhibitors have different coverage maps, in terms of both number and type of targeted kinases. Particularly, the number of kinases targeted by the FDA-approved anti-cancer kinase inhibitor drugs with dissociation constant $\left(K_{d}\right)$ values lower than 3 $\mu \mathrm{M}$ ranged from 3 kinases for lapatinib to 165 kinases for sunitinib, whereas for $K_{\mathrm{d}}$ values lower than $100 \mathrm{nM}$ the number of targeted kinases ranged from 2 kinases for gefinitib to 53 kinases for sunitinib [82] (Fig. 2). As an illustration of the different coverage maps of these class of drugs, in Fig. 3 the different kinases targeted by imatinib and sunitinib with $K_{\mathrm{d}}$ values lower than $100 \mathrm{nM}$ are shown. The different coverage maps of these drugs may explain some differences in their therapeutic profiles and the distinct types of cancer they are indicated for, as well as the fact that the more promiscuous sunitinib and dasatinib are useful in some types of cancer which are resistant to imatinib. 

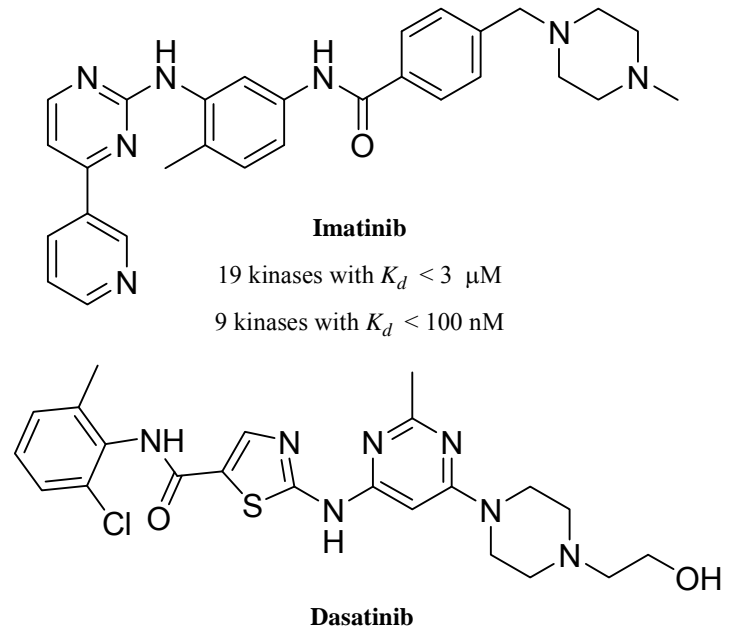

82 kinases with $K_{d}<3 \mu \mathrm{M}$

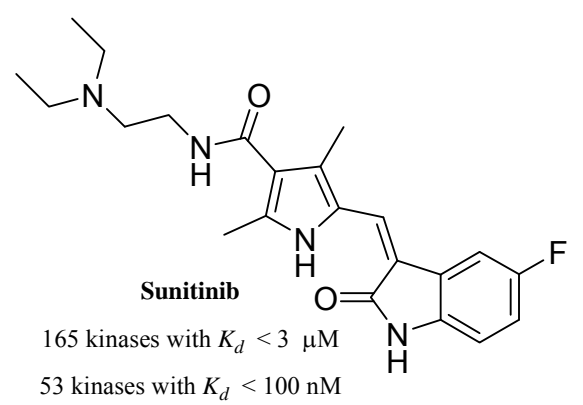

46 kinases with $K_{d}<100 \mathrm{nM}$<smiles>COc1cc2ncnc(Nc3ccc(F)c(Cl)c3)c2cc1OCCCN1CCOCC1</smiles>

21 kinases with $K_{d}<3 \mu \mathrm{M}$<smiles>C#Cc1cccc(Nc2ncnc3cc(OCCOC)c(OCCOC)cc23)c1</smiles>

44 kinases with $K_{d}<3 \mu \mathrm{M}$

4 kinases with $K_{d}<100 \mathrm{nM}$

2 kinases with $K_{d}<100 \mathrm{nM}$<smiles>CNC(=O)c1cc(Oc2ccc(NC(=O)Nc3ccc(Cl)c(C(F)(F)F)c3)cc2)ccn1</smiles>

52 kinases with $K_{d}<3 \mu \mathrm{M}$

14 kinases with $K_{d}<100 \mathrm{nM}$

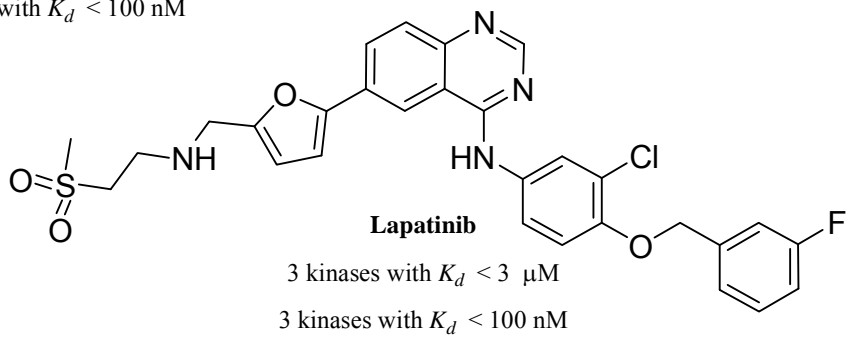

Fig. (2). Structures and number of kinases targeted with $K_{\mathrm{d}}<3 \mu \mathrm{M}$ and $100 \mathrm{nM}$ by marketed anti-cancer kinase inhibitor drugs. 


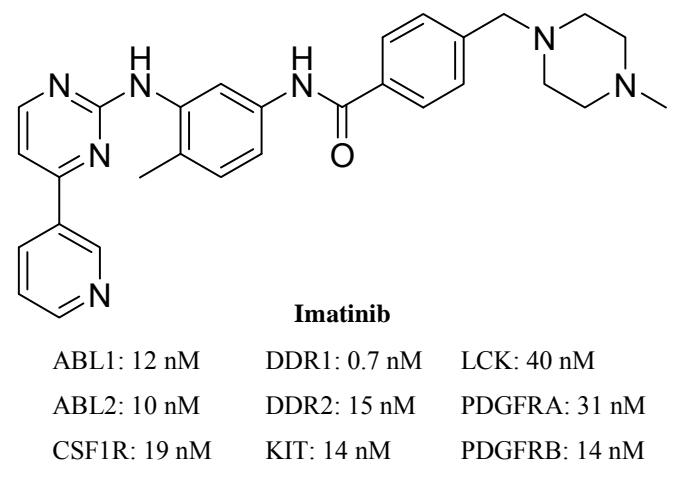

\begin{tabular}{|c|c|c|c|c|c|}
\hline \multicolumn{6}{|c|}{ Sunitinib } \\
\hline AAK1: $11 \mathrm{nM}$ & CLK2: $20 \mathrm{nM}$ & FLT3: $0.47 \mathrm{nM}$ & MAP4K5: $41 \mathrm{nM}$ & PDGFRB: $0.075 \mathrm{nM}$ & RPS6KA5: $28 \mathrm{nM}$ \\
\hline AMPK- $\alpha 1: 19 \mathrm{nM}$ & CLK4: $29 \mathrm{nM}$ & FLT4: $50 \mathrm{nM}$ & MERTK: $26 \mathrm{nM}$ & PHKG1: $5.5 \mathrm{nM}$ & SgK085: $15 \mathrm{nM}$ \\
\hline AMPK- $\alpha 2: 89 \mathrm{nM}$ & CSF1R: 2 nM & GAK: $20 \mathrm{nM}$ & MLCK: $23 \mathrm{nM}$ & PHKG2: $5.9 \mathrm{nM}$ & SLK: $56 \mathrm{nM}$ \\
\hline ARK5: $48 \mathrm{nM}$ & CSNK1D: $15 \mathrm{nM}$ & ITK: $13 \mathrm{nM}$ & MST1: $19 \mathrm{nM}$ & PIP5K2B: $39 \mathrm{nM}$ & STK33: $17 \mathrm{nM}$ \\
\hline AXL: $9 \mathrm{nM}$ & CSNK1E: $13 \mathrm{nM}$ & JAK1: $49 \mathrm{nM}$ & MST2: $56 \mathrm{nM}$ & PTK2B: $82 \mathrm{nM}$ & TNIK: $25 \mathrm{nM}$ \\
\hline BIKE: $5.5 \mathrm{nM}$ & CSNK2A1: $81 \mathrm{nM}$ & KIT: $0.37 \mathrm{nM}$ & MST3: $63 \mathrm{nM}$ & RET: $12 \mathrm{nM}$ & TTK: $63 \mathrm{nM}$ \\
\hline BLK: $65 \mathrm{nM}$ & DAPK3: $22 \mathrm{nM}$ & LKB1: $38 \mathrm{nM}$ & MYLK2: $49 \mathrm{nM}$ & RIOK1: $35 \mathrm{nM}$ & TYRO3: $49 \mathrm{nM}$ \\
\hline CAMK2A: $80 \mathrm{nM}$ & DRAK1: $1 \mathrm{nM}$ & LOK: $19 \mathrm{nM}$ & PAK3: $16 \mathrm{nM}$ & RPS6KA2: $17 \mathrm{nM}$ & VEGFR2: $1.5 \mathrm{nM}$ \\
\hline CLK1: $22 \mathrm{nM}$ & FLT1: $1.8 \mathrm{nM}$ & MAP4K1: $16 \mathrm{nM}$ & PDGFRA: $0.79 \mathrm{nM}$ & RPS6KA4: $96 \mathrm{nM}$ & \\
\hline
\end{tabular}

Fig. (3). Kinases targeted by imatinib and sunitinib with $K_{d}<100 \mathrm{nM}$.

Another example of extraordinarily promiscuous drug is clozapine (Clorazil ${ }^{\circledR}$, Fig. 4), the prototype of atypical antipsychotic drugs, which are among the most widely prescribed neuropsychiatric drugs $[40,85]$. The clinical superiority of atypical versus typical antipsychotics has been thought to result from a multitarget action on a number of postsynaptic biogenic amine G-protein-coupled receptors (GPCRs) [40]. Because a precise knowledge of the multitarget coverage map of clozapine is essential for enabling the design of optimized antipsychotic drugs, recently Yadav et al. have assessed the complex polypharmacological profile of clozapine by evaluating its activity against a 
panel of 2395 molecular targets, belonging to the GPCR, kinase, transporter, ion channel and enzyme classes [86]. By using a combination of experimental and chemoinformatic methods $[87,88]$, they found that clozapine, as well as another atypical antipsychotic drug, namely olanzapine, interacts potently with a unique set of biological targets, different from those targeted by the typical antipsychotic drug haloperidol, mainly involving higher affinity interactions with most human serotonin receptors and most muscarinic receptors and relatively lower affinity interactions with some dopamine receptors (Fig. 4). Within the complex coverage map of clozapine and olanzapine, the presynaptic component of the serotonin neuronal system has been identified as an essential mediator of their unique atypical antipsychotic action [86]. Thus, this presynaptic effect must be present together with a multitarget action at a plethora of postsynaptic receptors in the polypharmacological profile of next generations of antipsychotic drugs. 
<smiles>CN1CCN(C2=Nc3cc(Cl)ccc3Nc3ccccc32)CC1</smiles>

Clozapine<smiles>Cc1cc2c(s1)Nc1ccccc1N=C2N1CCN(C)CC1</smiles>

Olanzapine

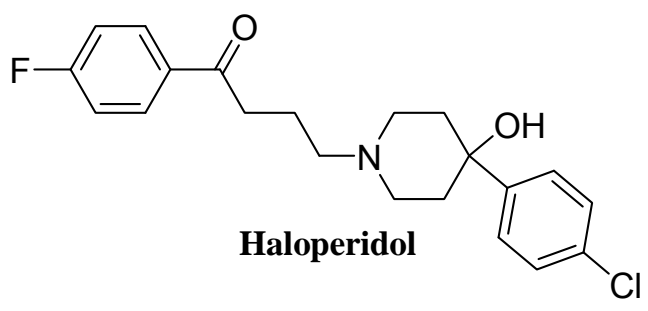

\begin{tabular}{|c|c|c|c|}
\hline Target & $\begin{array}{c}\text { Clozapine } \\
K_{\mathrm{i}}(\mu \mathrm{M})\end{array}$ & $\begin{array}{c}\text { Olanzapine } \\
K_{\mathrm{i}}(\mu \mathrm{M}) \\
\end{array}$ & $\begin{array}{c}\text { Haloperidol } \\
K_{\mathrm{i}}(\mu \mathrm{M}) \\
\end{array}$ \\
\hline 5-HT1A & 1.05 & & \\
\hline 5-HT1B & 3.98 & 5.09 & 1.65 \\
\hline 5-HT1E & 9.66 & & \\
\hline 5-HT2A & 0.13 & 0.03 & 0.73 \\
\hline 5-HT2C & 0.29 & 0.24 & \\
\hline 5-HT6 & 0.17 & 0.06 & \\
\hline 5-HT7 & 0.18 & 1.05 & 3.78 \\
\hline D1 & 1.89 & 0.58 & 0.83 \\
\hline D2 & 4.31 & 0.72 & 0.02 \\
\hline D3 & 6.46 & 0.63 & 0.12 \\
\hline D4 & 0.39 & 0.19 & 0.15 \\
\hline D5 & 2.35 & 0.90 & 1.47 \\
\hline H1 & 0.02 & 0.05 & \\
\hline $\mathrm{H} 2$ & 1.53 & 0.44 & \\
\hline $\mathrm{H} 4$ & 8.20 & & \\
\hline$\alpha 1 \mathrm{~A}$ & 0.02 & 1.09 & 0.12 \\
\hline$\alpha 1 B$ & 0.07 & 2.63 & 0.08 \\
\hline$\alpha 2 \mathrm{~A}$ & 1.42 & 3.14 & \\
\hline$\alpha 2 B$ & 0.27 & 0.82 & 4.80 \\
\hline$\alpha 2 \mathrm{C}$ & 0.34 & 0.29 & 5.50 \\
\hline M1 & 0.14 & 0.24 & \\
\hline M2 & 0.14 & 0.79 & \\
\hline M3 & 0.25 & 0.51 & \\
\hline M4 & 0.29 & 9.98 & \\
\hline M5 & 0.94 & 0.09 & 6.57 \\
\hline 5-HT3 & 2.41 & 2.02 & \\
\hline CHK2 & 1.99 & & \\
\hline
\end{tabular}

Fig. (4). Structure and multitarget profile of the atypical antipsychotic drugs clozapine and olanzapine compared with that of the typical antipsychotic drug haloperidol.

The successful antiepileptic drug levetiracetam $\left(\mathrm{Keppra}^{\circledR}\right)$ was developed as a selective modulator of the synaptic vesicle protein 2A (SV2A) $[17,89,90]$, and, indeed, optimization of the affinity at this single target led to the development of the more potent drug brivaracetam [91], which was considered a successful application of rational drug design in the frame of the reductionist approach. However, levetiracetam does not act specifically on this target, but it also hits a number of other molecular targets and 
events such as high-voltage activated calcium channels, delayed rectifier potassium current, calcium release from endoplasmic reticulum via the ryanodine, and the $\mathrm{IP}_{3}$ receptors, hippocampal protein expression and inflammation-impaired resting potential of astroglia (Fig. 5) [17]. It has been suggested that other antiepileptic drugs also exhibit multitarget profiles that mainly encompass modulation of several ion channel classes and that this promiscuity constitutes an important mechanistic clue to seizure treatment $[41,92,93]$.

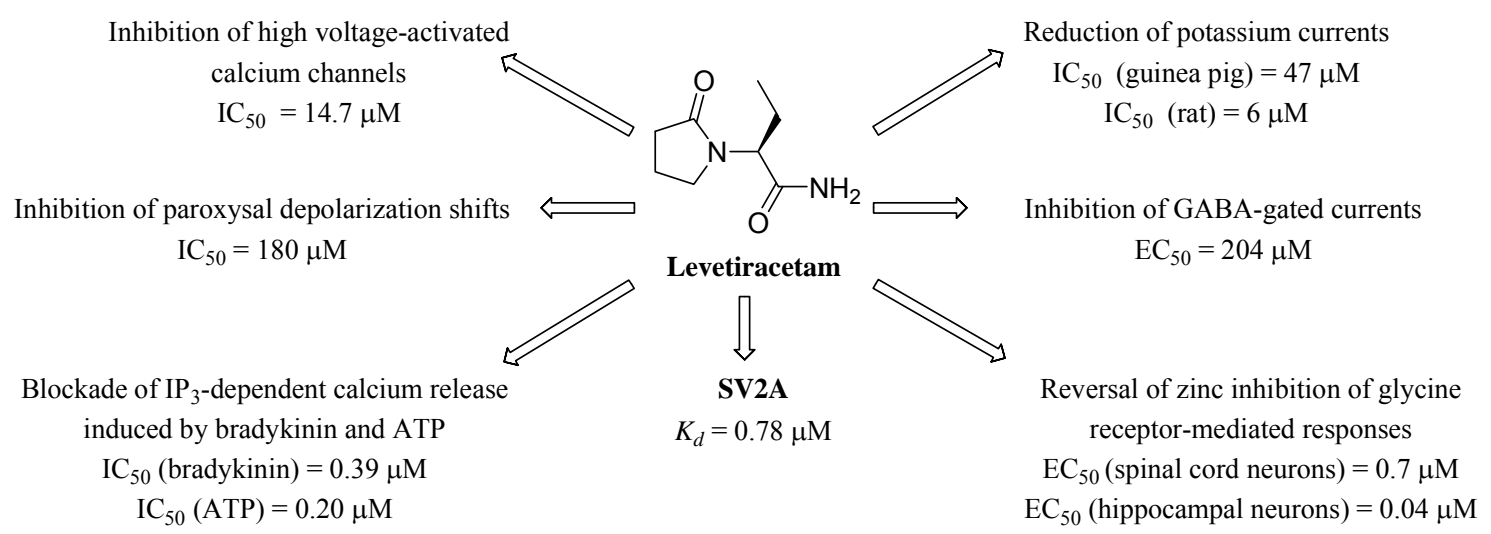

Fig. (5). Structure and multitarget profile of the antiepileptic drug levetiracetam.

\section{POLYPHARMACOLOGICAL THERAPEUTIC OPPORTUNITIES}

The conception of human diseases as complex pathological networks of interconnected proteins and the emergence of network pharmacology as a novel paradigm in drug discovery with a promising potential for deriving more efficacious and safer treatments have spurred important endeavors for deciphering the complexity of disease networks and of the polypharmacological profiles of most known drugs, with the final aim of enabling new therapeutic opportunities. These endeavors encompass either using the multitarget coverage maps of old drugs as the starting point for finding new therapeutic 
indications for these drugs or for designing derivatives thereof with modified profiles and different indications or for developing different types of multitarget therapeutic interventions involving either the simultaneous administration of several drugs or one single multitarget drug. These strategies will be only briefly discussed herein, as they will be presented in more detail in other articles of this issue [94-104].

\subsection{Drug Repositioning}

The proven facts that drugs usually act on multiple targets and that many protein targets appear to be relevant to several diseases provide the rational basis for the so-called drug repositioning or drug repurposing, a strategy aimed at finding new therapeutic applications for already approved drugs or even for drug candidates that did not reach the clinic for a particular indication from the knowledge of their multiple targets [96,105-109]. Assessment of the multitarget profile of known drugs can be carried out by extensive biological profiling and by application of computational methods $[17,19,75,88,110-114]$. Also, based on the rationale that drugs with a similar sideeffects profile should have a common mechanism of action, the study of the relationships known drugs-diseases and known drug-side-effects has been proposed as the starting point for finding new therapeutic indications for drugs with similar sideeffects profiles $[113,115]$.

Drug repositioning is emerging as rapid, low-risk, and cost-effective strategy of drug development, inasmuch is it usually starts from approved drugs, whose pharmacodynamic, pharmacokinetic, toxicological and galenic profiles are appropriate and perfectly established, thereby significantly reducing the risks associated to drug development and facilitating repositioned drugs to enter clinical trials more rapidly and less costly than in the case of novel drugs $[109,115,116]$. 


\subsection{Selective Optimization of Side Activities}

The multitarget profile of a known drug sometimes does not allow its direct repositioning for a new therapeutic indication and it has to be modified in such a way that initial low affinity interactions with some targets are optimized whereas initial high affinity interactions with other targets are minimized or abolished, so that the resulting coverage map is more suitable for the new therapeutic indication.

This selective optimization of side activities, the so-called SOSA approach [117-119], involves an initial screening of a library of known drugs followed by optimization of selected hits by a classical medicinal chemistry work, i.e. structural modification of the selected drugs to change the pharmacological profile as desired. Even though the safety and pharmacokinetic profiles of the drug analogs resulting from the optimization procedure are not known, the likelihood that these analogs will still exhibit druglike properties and therefore that will be suitable for further development is much higher than if the initial hits were not drugs safely used in humans but compounds with poor or unknown safety and bioavailability. Worthy of note, because the final analogs that have been optimized for the new therapeutic indication can be structurally quite different from the parent drug, and therefore structurally original, they may easily be out of the scope of the patents of the original drug and therefore patentable by themselves.

\subsection{Multitarget Therapies}

The logic behind network pharmacology inescapably leads to polypharmacological therapeutic approaches, i.e. the use of one drug or a combination of drugs to simultaneously hit several relevant protein targets of the disease network, as the most viable way to restore the physiological network state. This can be accomplished either 
by using combinations of two or more drugs each contained in a separate medicine (drug cocktails, polypharmacy) or in a single medicine (fixed-dose combinations (FDCs)), or by using single drugs with inherent or purposely designed ability to hit those selected multiple targets (multitarget drugs (MTDs)).

Use of combination therapies, classically drug cocktails and more recently FDCs, clearly represents the most established polypharmacological approach, it being a standard practice for the treatment of a number of diseases such as cancer, hypertension, atherosclerosis, diabetes, asthma, epilepsy, depression, anxiety disorders, AIDS, infectious diseases or pain therapy, among others $[7,19,120]$. Their main advantage is related with the possibility of dose flexibility [7,21], which is a very important issue for the optimal balance of potencies with which the different molecular targets need to be hit. This is especially feasible in drug cocktails, where each medicine can be administered at the needed dose, which might be even changed during patient monitoring, thereby allowing a change of the molecular ratio of the different drugs of the combination during the treatment. Dose flexibility in FDCs is lower because the molecular ratio of the different component drugs is by definition fixed when the medicine is formulated, but at least molecular ratios different from one-to-one between the different drugs are possible.

The multidrug nature of drug cocktails and FDCs, which may be advantageous for dose flexibility, turns into a disadvantage when considering other important issues, namely i) the occurrence of drug-drug interactions that might accelerate or reduce the metabolism of some of the component drugs, which added to the different relative rates of metabolism of the component drugs between patients due to genetic polymorphism and to the likely inherent promiscuous profile of each component drug, will lead to unexpected and complex pharmacokinetic and pharmacodynamic relationships and to 
unpredictable variability of effect between patients [21]; ii) the need for more complex and expensive clinical trials and more strict regulatory requirements, as efficacy and safety has to be demonstrated for each component drug separately and in combination $[19,121,122]$; iii) a reduced molecular target space, as most drug combinations involve the use of already known drugs, and therefore a reduced potential for innovation [19]; or iv) increased potential for side-effects derived from the addition of the side-effects of each component drug [123].

Indeed, a major disadvantage of drug cocktails and FDCs is the risk of drug-drug interactions. This risk is so significant that the use of drug cocktails has been also proposed for a completely different use, namely as a screening tool for the characterization of potential in vivo drug-drug interactions to discard drug candidates with unacceptable drug interaction profile in the early phases of the drug discovery process [124]. Some experimental and theoretical methods are being developed for designing optimal drug combinations for therapeutic use, with minimized problems associated with drug-drug interactions [76,125-128].

The main particularity of drug cocktails, which clearly differentiates them from the other strategies, is their multi-medicine or polypharmacy nature, which leads to very important drawbacks such as poor patient compliance and inappropriate drug use [123]. These issues can be circumvented by the single-medicine approaches (FDCs and MTDs), which involve simpler dosing regimens and better treatment adherence $[123,129,130]$.

A particular issue of FDCs is related with the galenic difficulties that can be found in the co-formulation of several drugs into a single medicine, mainly derived from the chemical stability and potential chemical or physical interactions between component drugs in the combination $[120,131]$. Worthy of note, development of FDCs has not been 
devoid of some criticism of commercial opportunism, as in some cases it might be driven by factors other than scientific or clinical innovation, for example extension of patent protection of a blockbuster drug going off patent by introducing it into a new FDC ("evergreening") or introduction of a new drug, which might be hazardous or inefficacious, together with one or more already marketed drugs into a new FDCs ("bundling") [122]. Also, some uncertainty about the clinical efficacy and safety of component drugs of a FDC may exist in particular cases which involve the concurrent development of two or more new unmarketed drugs into a combination, the so-called codevelopment $[35,132]$. According to a recent FDA guidance codevelopment should be restricted for combinations of new drugs against difficult-to-treat diseases, for which there are both compelling biological rationale and preclinical or short-term clinical results that support the superiority of the combination relative to the component drugs alone, and for cases where individual drugs cannot be developed individually [132].

Overall, the best polypharmacological treatment option seems to be the use of MTDs, inasmuch as they benefit from the higher patient compliance associated to singlemedicine approaches, and from additional particular advantages derived from their single-drug nature. As in the development process of every new chemical entity, the development of MTDs is much easier than that of multi-drug approaches, as it involves much simpler pharmacokinetic and pharmacodynamic assessment, lower regulatory barriers, and simpler clinical trials and drug registration procedures. Also, the increasing availability of disease-associated protein-interaction networks will allow the selection of a high number of combinations of multiple, in many cases unexpected, protein targets to be hit by MTDs, thereby increasing the biological target space and the potential for innovation [74]. 
However, MTDs are also associated to some limitations, mainly the difficulty, but not impossibility, for balancing the most appropriate ratio of potencies of the drug at its different targets, a problem that in multi-drug therapies can be overcome by adjusting the doses of the different drugs. In every case, this is also feasible for MTDs as evidenced by the clinical efficacy of many known drugs, retrospectively found to be inherently multitarget, but also of some rationally designed MTDs [133].

The discovery of novel MTDs can be basically carried out through two different procedures that involve the multitarget screening of compound libraries or the rational design of MTDs by combination in a single molecule of two pharmacophoric moieties with ability to interact with different primary biological targets, the so-called framework or pharmacophore combination approach [21,95,130,134-137], which differ not only in the way they are carried out but also in the structural complexity of the derived multitarget compounds. Not surprisingly, compounds that result from the application of the framework combination approach tend to be larger and structurally more complex molecules than inherently multitarget compounds found in screening campaigns. The difficult-to-refuse argument that human diseases, as complex pathological networks, will be better treated by drugs with a complex multitarget pharmacological profile, and therefore that complexity must be tackled with complexity, does not necessarily apply, however, when structural complexity of MTDs is considered. Indeed, structural complexity seems to be detrimental for polypharmacology [136]. Increased structural complexity leads to an increased probability of geometrical and electronic complementarity mismatch between the drug and the binding site of any given target, thereby dramatically diminishing the likelihood of hitting a selective combination of targets $[4,136,138,139]$. The fact that the framework combination approach usually leads to large molecules has clear negative implications not only regarding the 
purported multitarget profile but also the pharmacokinetic profile, as large molecules are usually endowed with poor oral absorption. An appropriate selection of the combination of targets to be hit as well as the adjustment of the ratio of activities at the different targets and druglike physicochemical properties constitute very important challenges for medicinal chemists devoted to the development of novel MTDs $[7,134,135,140]$.

\section{CONCLUSIONS}

As network biology perspectives are bursting into the drug discovery scenario it is becoming increasingly apparent that design of exquisitely selective drugs in the frame of the dominant one-disease, one-gene, one-protein, one-drug philosophy is very likely to fall short of deriving efficacious and safe new drugs, inasmuch as it is being carried out completely disregarding the complex biological context where protein targets and drugs act. Indeed, it has been found that human diseases do not usually result from one but from several causative factors, and, consequently, there should not be one but several relevant protein targets to be hit, which do not work on isolation but in a highly interconnected manner by forming complex interaction networks with many other cellular components. Very interestingly, it has been also found that most known drugs exhibit a multitarget profile, irrespective of the fact that many of them were designed as and initially considered to be exquisitely selective toward a particular target, and that their multitarget profile, far from leading to toxicity, is instead directly involved in their clinical efficacy. Overall, it might be even thought that in most cases the one-disease, one-gene, one-protein, one-drug philosophy might be Utopian. Along with this, network pharmacology and the notion that the complexity of human disease has to be faced up with a complex polypharmacological therapeutic intervention are gaining 
credence among drug discoverers. In this light, the quite common practice of prescribing drug cocktails is now more meaningful than ever, whereas important efforts are being made for developing new multitarget therapies, mainly in the form of FDCs or MTDs.

Network biology is still in its infancy, but as our knowledge about interaction networks increases, multitarget drug discovery programs, which are currently minor in pharmaceutical industry, will certainly spread, slowly replacing single-target-based strategies and offering new hopes for the emergence of crucial efficacious and safe new treatments for so far intractable diseases and exciting prospects for increased revenues of the pharmaceutical industry.

\section{ACKNOWLEDGEMENTS}

The authors gratefully acknowledge Dr. Patrick Aloy and Dr. Roberto Mosca, of the Institut de Recerca Biomèdica (IRB Barcelona, Spain), for providing the figure of the protein interaction network associated to Alzheimer's disease.

\section{REFERENCES}

[1] Lee, J.A.; Uhlik, M.T.; Moxham, C.M.; Tomandl, D.; Sall, D. Modern phenotypic drug discovery is a viable, neoclassic pharma strategy. J. Med. Chem., 2012, 55, 4527-4538.

[2] Macarron, R.; Banks, M.N.; Bojanic, D.; Burns, D.J.; Cirovic, D.A.; Garyantes, T.; Gree, D.V.; Hertzberg, R.P.; Janzen, W.P.; Paslay, J.W.; Schopfer, U.; Sittampalam, G.S. Impact of high-throughput screening in biomedical research. Nat. Rev. Drug Discov., 2011, 10, 188-195. 
[3] Huang, S. Rational drug discovery: what can we learn from regulatory networks? Drug Discov. Today, 2002, 7, S163-169.

[4] Janga S.C.; Tzakos, A. Structure and organization of drug-target networks: insights from genomic approaches for drug discovery. Mol. BioSyst., 2009, 5, $1536-1548$.

[5] Hopkins, A.L. Network pharmacology. Nat. Biotechnol., 2007, 25, 1110-1111.

[6] Kauffman, S.H.E. Paul Ehrlich: founder of chemotherapy. Nat. Rev. Drug Discov., 2008, 7, 373.

[7] Costantino, L.; Barlocco, D. Designed multiple ligands: basic research vs clinical outcomes. Curr. Med. Chem., 2012, 19, 3353-3387.

[8] Betz, U.A.K. How many genomics targets can a portfolio afford? Drug Discov. Today, 2005, 10, 1057-1063.

[9] Drews, J. Drug industry in “depression”. Med. Sci. Monit., 2005, 11, SR1-SR4.

[10] Overington, J.P.; Bissan, A.; Hopkins, A. How many drug targets are there? Nat. Rev. Drug. Discov., 2006, 5, 993-996.

[11] Yildirim, M.A.; Goh, K.I.; Cusick, M.E.; Barabasi, A.L.; Vidal, M. Drug-target network. Nat. Biotechnol., 2007, 25, 1119-1126.

[12] Booth, B.; Zemmel, R.; Prospects for productivity. Nat. Rev. Drug Discov., 2004, 3, 451-456.

[13] Swinney, D.C.; Anthony, J. How were new medicines discovered? Nat. Rev. Drug Discov., 2011, 10, 507-519.

[14] Kola, I.; Landis, J. Can the pharmaceutical industry reduce attrition rates? Nat. Rev. Drug Discov., 2004, 3, 711-716.

[15] Cohen, F.J. Macro trends in pharmaceutical innovation. Nat. Rev. Drug Discov., 2005, 4, 78-84. 
[16] Sams-Dodd, F. Target-based drug discovery: is something wrong? Drug Discov. Today, 2005, 10, 139-147.

[17] Margineanu, D.G. Systems biology impact on antiepileptic drug discovery. Epilepsy Res., 2012, 98, 104-115.

[18] van der Greef, J.; MacBurney, R.N. Rescuing drug discovery: in vivo systems pathology and systems pharmacology. Nat. Rev. Drug Discov., 2005, 4, 961967.

[19] Hopkins, A.L. Network pharmacology: the next paradigm in drug discovery. Nat. Chem. Biol., 2008, 4, 682-690.

[20] Pujol, A.; Mosca, R.; Farrés, J.; Aloy, P. Unveiling the role of network and systems biology in drug discovery. Trends Pharmacol. Sci., 2010, 31, 115-123.

[21] Morphy, R.; Rankovic, Z. Designed multiple ligands. An emerging drug discovery paradigm. J. Med. Chem., 2005, 48, 6523-6543.

[22] Lansbury, P.T., Jr. Back to the future: the "old-fashioned" way to new medication for neurodegeneration. Nat. Rev. Neurosci., 2004, 5, S51-S57.

[23] Barabasi, A.L.; Oltvai, Z.N.; Network biology: understanding the cell's functional organization. Nat. Rev. Genet., 2004, 5, 101-113.

[24] Vidal, M. Interactome modeling. FEBS Lett., 2005, 579, 1834-1838.

[25] Stein, A.; Mosca, R.; Aloy, P. Three-dimensional modeling of protein interactions and complexes is going 'omics. Curr. Opin. Struct. Biol., 2011, 21, 200-208.

[26] Ellis, R.J.; Minton, A.P. Joint he crowd. Nature, 2003, 425, 27-28.

[27] Ellis, R.J. Macromolecular crowding: Obvious but underappreciated. Trends Biochem. Sci., 2001, 26, 597-604. 
[28] Hall, D.; Minton, A.P. Macromolecular crowding: Qualitative and semiquantitative successes, quantitative challenges. Biochim. Biophys. Acta, 2003, 1649, 127-139.

[29] Csermely, P.; Agoston, V.; Pongor, S. The efficiency of multi-target drugs: the network approach might help drug design. Trends Pharmacol. Sci., 2005, 29, $178-182$.

[30] Chen, Y.; Zhu, J.; Lum, P.Y.; Yang, X.; Pinto, S. MacNeil, D.J.; Zhang, C.; Lamb, J.; Edwards, S.; Sieberts, S.K.; Leonardson, A.; Castellini, L.W.; Wang, S.; Champy, M.F.; Zhang, B.; Emilsson, V.; Doss, S.; Ghazalpour, A.; Horvath, S.; Drake, T.A.; Lusis, A.J.; Schadt, E.R. Variations in DNA elucidate molecular networks that cause disease. Nature, 2008, 452, 429-435.

[31] Kitano, H. Systems biology: a brief overview. Science, 2002, 295, 1662-1664.

[32] Zanzoni, A.; Soler-López, M.; Aloy, P. A network medicine approach to human disease. FEBS Lett., 2009, 583, 1759-1765.

[33] Kitano, H. Biological robustness. Nat. Rev. Genet., 2004, 5, 826-837.

[34] Kitano, H. A robustness-based approach to systems-oriented drug design. Nat. Rev. Drug Discov., 2007, 6, 202-210.

[35] Woodcock, J.; Griffin, J.P.; Behrman, R.E. Development of novel combination therapies. N. Engl. J. Med., 2011, 17, 985-987.

[36] Albert, R.; Jeong, H.; Barabasi, A.L. Error and attack tolerance of complex networks. Nature, 2000, 406, 378-382.

[37] Kitano, H. Towards a theory of biological robustness. Mol. Syst. Biol., 2007, 3, 137. 
[38] Cho, C.R.; Labow, M.; Reinhardt, M.; van Oostrum, J.; Peitsch, M.C. The application of systems biology to drug discovery. Curr. Opin. Chem. Biol., 2006, 10, 294-302.

[39] Mencher, S.K.; Wang, L.G. Promiscuous drugs compared to selective drugs (promiscuity can be a virtue). BMC Clin. Pharmacol., 2005, 5, 3.

[40] Roth, B.L.; Scheffler, D.J.; Kroeze, W.K. Magic shotguns versus magic bullets: selectively non-selective drugs for mood disorders and schizophrenia. Nat. Rev. Drug Discov., 2004, 3, 353-359.

[41] Bianchi, M.T.; Pathmanathan, J.; Cash, S.S. From ion channels to complex networks: magic bullet versus magic shotgun approaches to anticonvulsant pharmacotherapy. Med. Hypotheses, 2009, 72, 297-305.

[42] Jia, J.; Zhu, F.; Ma, X.; Cao, Z.W.; Li, Y.X.; Chen, Y.Z. Mechanisms of drug combinations: interaction and network perspectives. Nat. Rev. Drug Discov., 2009, 8, 111-128.

[43] Erickson, R.P. From "magic bullet" to "specially engineered shotgun loads": the new genetics and the need for individualized pharmacotherapy. Bioessays, 1998, 20, 683-685.

[44] Stephenson, V.C.; Heyding, R.A.; Weaver, D.F. "The promiscuous drug concept" with applications to Alzheimer's disease. FEBS Lett., 2005, 579, 13381342.

[45] Bianchi, M.T.; Botzolakis, E.J. Targeting ligand-gated channels in neurology and psychiatry: is pharmacological promiscuity an obstacle or an opportunity? BMC Pharmacol., 2010, 10, 3.

[46] Fields, S.; Song, O. A novel genetic system to detect protein-protein interactions. Nature, 1989, 340, 245-246. 
[47] Eyckerman, S.; Lemmens, I.; Catteeuw, D.; Verhee, A.; Vandekerckhove, J.; Lievens, S.; Tavernier, J. Reverse MAPPIT: screening for protein-protein interaction modifiers in mammalian cells. Nat. Methods, 2005, 2, 427-433.

[48] Paumi, C.M.; Menendez, J.; Arnoldo, A.; Engels, K.; Iyer, K.R.; Thaminy, S.; Georgiev, O.; Barral, Y.; Michaelis, S.; Stagljar, I. Mapping protein-protein interactions for yeast $\mathrm{ABC}$ transporter Ycflp by integrated split ubiquitin membrane yeast two-hybrid analysis. Mol. Cell, 2007, 26, 15-25.

[49] Jansen, R.; Yu, H.; Greenbaum, D.; Kluger, Y.; Krogan, N.J.; Chung, S.; Emili, A.; Snyder, M.; Greenblatt, J.F.; Gerstein, M. A Bayesian networks approach for predicting protein-protein interactions from genomic data. Science, 2003, 302, 449-453.

[50] Lu, L.J.; Xia, Y.; Yu, H.; Rives, A.; Lu, H.; Schubert, F.; Gerstein, M.B. Protein interaction prediction by integrating genomic features and protein interaction network analysis. In: Data Analysis and Visualization in Genomics and Proteomics; Azuaje, F.; Dopazo, J. Eds.; Wiley: 2005, pp. 61-81.

[51] Shen, J.; Zhang, J.; Luo, X.; Zhu, W.; Yu, K.; Chen, K.; Li, Y.; Jiang, H. Predicting protein-protein interactions based only on sequences information. Proc. Natl. Acad. Sci. U.S.A., 2007, 104, 4337-4341.

[52] Jensen, L.J.; Kuhn, M.; Stark, M.; Chaffron, S.; Greevey, G.; Muller, J.; Doerks, T.; Julien, P.; Roth, A.; Simonovic, M.; Bork, P.; von Mering, C. STRING 8-a global view on proteins and their fujnctional interactions in 630 organisms. Nucleic Acids Res., 2009, 37, D412-416.

[53] Zhang, M.; Su, S.; Bhatnagar, R.K.; Hasset, D.J.; Lu, L.J. Prediction and analysis of the protein interactome in Pseudomonas aeruginosa to enable network-based drug target selection. PLOS ONE, 2012, 7, e41202. 
[54] Schadt, E.E.; Friend, S.H.; Shaywitz, D.A. A network view of disease and compound screening. Nat. Rev. Drug. Discov., 2009, 8, 286-295.

[55] Uetz, P.; Giot, L.; Gagney, G.; Mansfield, T.A.; Judson, R.S.; Knight, J.R.; Lockshon, D.; Narayan, V.; Srinivasan, M.; Pochart, P.; Qureshi-Emili, A.; Li, Y.; Dodwin, B.; Conover, D.; Kalbfleisch, T.; Vijayadamodar, G.; Yang, M.; Johnston, M.; Fields, S.; Rothberg, J.M. A comprehensive analysis of protein-protein interactions in Saccharomyces cerevisiae. Nature, 2000, 403, 623-627.

[56] Ito, T.; Chiba, T.; Ozawa, R.; Yoshida, M.; Hattori, M.; Sakaki, Y. A comprehensive two-hybrid analysis to explore the yeast protein interactome. Proc. Natl. Acad. Sci. U.S.A., 2001, 98, 4596-4574.

[57] Gabin, A.C.; Aloy, P.; Grandi, P.; Krause, R.; Boesche, M.; Marzioch, M.; Rau, C.; Jensen, L.J.; Bastuck, S.; Dümpelfeld, B.; Edelmann, A.; Heurtier, M.A.; Hoffman, V.; Hoefert, C.; Klein, K.; Hudak, M.; Michon, A.M.; Schelder, M.; Schirle, M.; Remor, M.; Rudi, T.; Hooper, S.; Bauer, A.; Bouwmeester, T.; Casari, G .; Drewes, G.; Neubauer, G.; Rick, J.M.; Kuster, B.; Bork, P.; Russell, R.P.; Superti-Furga, G. Proteome survey reveals modularity of the yeast call machinery. Nature, 2006, 440, 631-636.

[58] Krogan, N.J.; Cagney, G.; Yu, H.; Zhong, G.; Guo, X.; Ignatchenko, A.; Li, J.; Pu, S.; Datta, N.; Tikusis, A.P.; Punna, T.; Peregrín-Alvarez, J.M.; Shales, M.; Zhang, X.; Davey, M.; Robinson, M.D.; Paccanaro, A.; Bray, J.E.; Sheung, A.; Beattie, B.; Richards, D.P.; Canadien, V.; Lalev, A.; Mena, F.; Wong, P.; Starostine, A.; Canete, M.M.; Vlasblom, J.; Wu, S.; Orsi, C.; Collins, S.R.; Chandran, S.; Haw, R.; Rilstone, J.; Gandi, K.; Thompson, N.J.; Musso, G.; St Onge, P, Ghanny, S.; Lam, M.H.Y.; Butland, G.; Altaf-Ul, A.M.; Kanaya, S.; 
Shilatifard, A.; O’Shea, E.; Weissman, J.S.; Ingles, C.J.; Hughes, T.R.; Parkinson, J.; Gerstein, M.; Wodak, S.J.; Emili, A.; Greenblatt, J.F. Global landscape of protein complexes in the yeast Saccharomyces cerevisiae. Nature, 2006, 440, 637-643.

[59] Guiot, L.; Bader, J.S.; Brower, C.; Chadhuri, A.; Kuang, B.; Li, Y.; Hao, Y.L.; Ooi, C.E.; Godwin, B.; Vitols, E.; Vijayadamodar, G.; Pochsrt, P.; Machineni, H.; Welsh, M.; Kong, Y.; Zerhusen, B.; Malcolm, R.; Varrone, Z.; Collis, A.; Minto, M.; Burgess, S.; McDaniel, L.; Stimpson, E.; Springgs, F.; Williams, J.; Neurath, K.; Ioime, N.; Agee, M.; Voss, E.; Furtak, K.; Renzulli, R.; Aanesen, N.; Carrolla, S.; Bickelhaup, E.; Lazovastky, Y.; DaSilva, A.; Zhong, J.; Stanyon, C.A.; Finley Jr., R.L.; White, K.P.; Braveman, M.; Jarvie, T.; Gold, S.; Leach, M.; Knight, J.; Shimkets, R.A.; McKenna, M.P.; Chant, J.; Rothberg, J.M. A protein interaction map of Drosophila melanogaster. Science, 2003, 302, $1727-1736$.

[60] Li, S.; Armstrong, C.M.; Bertin, N.; Ge, H.; Milstein, S.; Boxem.; M.; Vidalain, P.O.; Han, J.D.J.; Chesneau, A.; Hao, T.; Goldberg, D.S.; Li, N.; Martinez, M.; Rual, J.F.; Lamesch, P.; Xu, L.; Tewari, M.; Wong, S.L.; Zhang, L.V.; Berriz, G.F.; Jacotot, L.; Vaglio, P.; Reboul, J.; Hirozane-Kishikawa, T.; Li, Q.; Gabel, H.W.; Elewa, A.; Baumgartner, B.; Rose, D.J.; Yu, H.; Bosak, S.; Sequerra, R.; Fraser, A.; Mango, S.E.; Saxton, W.M.; Strome, S.; den Heuvel, S.; Piano, F.; Vandenhaute, J.; Sardet, C.; Gerstein, M.; Doucette-Stamm, Gunsauls, K.C.; L.; Harper, J.W.; Cusick, M.E.; Roth, F.P.; Hill, D.E.; Vidal, M. A map of the interactome network of the metazoan C. elegans. Science, 2004, 303, 540-543.

[61] Rual, J.F.; Venkatesan, K.; Hao, T.; Hirozane-Kishiwaka, T.; Dricot, A.; Li, N.; Berriz, G.F.; Gibbons, F.D.; Dreze, M.; Ayivi-Guedehoussou, N.; Klitgord, N.; 
Simon, C.; Boxem, M.; Milstein, B.; Rosenberg, J.; Goldberg, D.S.; Zhang, L.V.; Wong, S.L.; Franklin, G.; Li, S.; Albala, J.S.; Lim, J.; Fraughton, C.; Llamosas, E.; Cevik, S.; Bex, C.; Lamesch, P.; Sikorski, R.S.; Vandenhaute, J.; Zoghbi, H.Y.; Smolyar, A.; Bosak, S.; Sequerra, R.; Doucette-Stamm, L.; Cusick, M.E.; Hill, D.E.; Roth, F.P.; Vidal, M. Towards a proteome-scale map of the human protein-protein interaction network. Nature, 2005, 437, 11731178.

[62] Stelzl, U.; Worm, U.; Lalowski, M.; Haenig, C.; Brembeck, F.H.; Goehler, H.; Stroedicke, M.; Zenkner, M.; Schoenherr, A.; Koeppen, S.; Timm, J.; Mintzlaff, S.; Abraham, C.; Bock, N.; Kietzmann, S.; Goedde, A.; Toksöz, E.; Droege, A.; Krobitsch, S.; Korn, B.; Birchmeier, W.; Lehrach, H.; Wanke, E.E. A human protein-protein interaction network: a resource for annotating the proteome. Cell, 2005, 122, 957-968.

[63] Ewing, R.M.; Chu, P.; Elisma, F.; Li, H.; Taylor, P.; Climie, S.; McBroomCerajewski, L.; Robinson, M.D.; O’Connor, L.; Li, M.; Taylor, R.; Dharsee, M.; Ho, Y.; Heilbut, A.; Moore, L.; Zhang, S.; Ornatsky, O.; Bukhman, Y.V.; Ethier, M.; Sheng, Y.; Vasilescu, J.; Abu-Farha, M.; Lambert, J.P.; Duewel, H.S.; Stewart, I.I,; Kuehl, B.; Hogue, K.; Colwill, K.; Gladwish, K.; Muskat, B.; Kinach, R.; Adams, S.L.; Moran, M.F.; Morin, G.B.; Topaloglou, T.; Figeys, D. Large-scale mapping of human protein-protein interactions by mass spectrometry. Mol. Syst. Biol., 2007, 3, 89.

[64] Soler-López, M.; Zanzoni, A.; Lluís, R.; Stelzl, U.; Aloy, P. Interactome mapping suggests new mechanistic details underlying Alzheimer's disease. Genome Res., 2011, 21, 364-376. 
[65] Charbonnier, S.; Gallego, O.; Gavin, A.C. The social network of cell: recent advances in interactome mapping. Biotechnol. Annu. Rev., 2008, 38, D532D539.

[66] Soler-López, M.; Badiola, N.; Zanzoni, A.; Aloy, P. Towards Alzheimer's root cause: ECSIT as an integrating hub between oxidative stress, inflamation and mitochondrial dysfunction. Bioessays, 2012, 34, 532-541.

[67] Shirasaki, D.I.; Greiner, E.R.; Al-Ramahi, I.; Gray, M.; Boontheung, P.; Geschwind, D.H.; Botas, J.; Coppola, G.; Horvath, S.; Loo, J.A.; Yang, W. Network organization of the huntingtin proteomic interactome in mammalian brain. Neuron, 2012, 75, 41-57.

[68] Huang, H.; Jedynak, B.M.; de Silva, E.; Stewart, R.; An, H.J.; Lappe, M.; Wiuf, C. Estimating the size of the human interactome. Proc. Natl. Acad. Sci. U.S.A., 2008, 105, 6959-6964.

[69] Goh, K.-I.; Cusick, M.E.; Valle, D.; Childs, B.; Vidal, M.; Barabasi, A.-L. The human disease network. Proc. Natl. Acad. Sci. U.S.A., 2007, 104, 8685-8690.

[70] Nacher, J.C.; Schwartz, J.-M. A global view of drug-therapy interactions. BMC Pharmacol., 2008, 8, 5.

[71] Yu, H.; Chen, J.; Xu, X.; Li, Y.; Zhao, H.; Fang, Y.; Li, X.; Zhou, W.; Wang, W.; Wang, Y. A systematic prediction of multiple drug-target interactions from chemical, genomic, and pharmacological data. PLoS One, 2012, 7, 1-14.

[72] Yung, L.; Chen, J.; Shi, L.; Hudock, M.P.; Wang, K.; He, L. Identifying unexpected therapeutic targets via chemical-protein interactome. PLoS One, 2010, $5,1-11$. 
[73] Mestres, J.; Gregori-Puigjane, E.; Valverde, S.; Sole, R.V. The topology of drug-target interaction networks: implicit dependence on drug properties and target families. J. Mol. BioSyst., 2009, 5, 1051-1057.

[74] Mestres, J.; Gregori-Puigjané, E.; Valverde, S.; Solé, R.V. Data completenessThe Achilles heel of drug-target networks. Nat. Biotechnol., 2008, 26, 983-984.

[75] Hopkins, A.L. Predicting promiscuity. Nature, 2009, 462, 167-168.

[76] Keith, C.T.; Borisy, A.A.; Stockwel, B.R. Multicomponent therapeutics for networked systems. Nat. Rev. Drug Discov., 2005, 4, 71-78.

[77] Frantz, S. Drug discovery: playing dirty. Nature, 2005, 437, 942-943.

[78] Hampton, T. "Promiscuous" anticancer drugs that hit multiple targets may thwart resistance. JAMA, 2004, 292, 419-422.

[79] Capdeville, R.; Buchdunger, E.; Zimmermann, J.; Matter, A. Glivec (STI571, imatinib), a rationally developed, targeted anticancer drug. Nat. Rev. Drug Discov., 2002, 1, 493-502.

[80] Giles, F.J.; O’Dwyer, M.; Swords, R. Class effects of tyrosine kinase inhibitors in the treatment of chronic myeloid leukemia. Leukemia, 2009, 23, 1698-1707.

[81] Drews, J. Case histories, magic bullets and the state of drug discovery. Nat. Rev. Drug. Discov., 2006, 5, 635-640.

[82] Karaman, M.W.; Herrgard, S.; Treiber, D.K.; Gallant, P.; Atteridge, C.E.; Campbell, B.T.; Chan, K.W.; Ciceri, P.; Davis, M.I; Edeen, P.T.; Faraoni, R.; Floyd, M.; Hunt, J.P.; Lockhart, D.J.; Milanov, Z.V.; Morrison, M.J.; Pallares, G.; Patel, H.K.; Pritchard, S.; Wodicka, L.M.; Zarrinkar, P. A quantitative analysis of kinase inhibitor selectivity. Nat. Biotechnol., 2008, 26, 127-132.

[83] Knight, Z.A.; Lin, H.; Shokat, K.M. Targeting the cancer kinome through polypharmacology. Nat. Rev. Cancer, 2010, 10, 130-137. 
[84] Faivre, S.; Demetri, G.; Sargent, W.; Raymond, E. Molecular basis for sunitinib efficacy and future clinical development. Nat. Rev. Drug Discov., 2007, 6, 734745.

[85] Lieberman, J.A.; Stroup, T.S.; McEvoy, J.P.; Swartz, M.S.; Rosenheck, R.A.; Perkins, D.O.; Keefe, R.S.E.; Davis, S.M.; Davis, C.E.; Lebowitz, B.D.; Severe, J.; Hsiao, J.K. Effectiveness of antipsychotic drugs in patients with chronic schizophrenia. N. Engl. J. Med., 2005, 353, 1209-1223.

[86] Yadav, P.N.; Abbas, A.I.; Farrell, M.S.; Setola, V.; Sciaky, N.; Huang, X.-P.; Kroeze, W.K.; Crawford, L.K.; Piel, D.A.; Keiser, M.J.; Irwin, J.J.; Schoichet, B.K.; Deneris, E.S.; Gingrich, J.; Beck, S.G.; Roth, B.L. The presynaptic component of the serotonergic system is required for clozapine's efficacy. Neuropsychopharmacol., 2011, 36, 638-651.

[87] Keiser, M.J.; Roth, B.L.; Armbruster, B.N.; Ernsberger, P.; Irwin, J.J.; Shoichet, B.K. Relating protein pharmacology by ligand chemistry. Nat. Biotechnol., 2007, 25, 197-206.

[88] Keiser, M.J.; Setola, V.; Irwin, J.J.; Laggner, C.; Abbas, A.I.; Hufeisen, S.J.; Jensen, N.H.; Kuijer, M.B.; Matos, R.C.; Tran, T.B.; Whaley, R.; Glennon, R.A.; Hert, J.; Thomas, K.L.H.; Edwards, D.D.; Shoichet, B.K.; Roth, B.L. Predicting new molecular targets for known drugs. Nature, 2009, 462, 175-182.

[89] Lynch, B.A:; Lambeng, N.; Nocka, K.; Kensel-Hammes, P.; Bajjalieh, S.M.; Matagne, A.; Fuks, B. The synaptic vesicle protein SV2A is the binding site for the antiepileptic drug levetirazetam. Proc. Natl. Acad. Sci. U.S.A., 2004, 101, 9861-9866.

[90] Brodie, M.J.; Kwan, P. Staged approach to epilepsy management. Neurology, 2002, 58, S2-S8. 
[91] Rogawski, M.A. Brivaracetam: a rational drug discovery success story. J. Pharmacol., 2008, 154, 1555-1557.

[92] Rogawski, M.A.; Löscher, W. The neurobiology of antiepileptic drugs. Nat. Rev. Neurosci., 2004, 5, 553-564.

[93] Bianchi, M.T. Promiscuous modification of ion channels by anti-psychotic and anti-dementia medications. Med. Hypotheses, 2010, 74, 297-300.

[94] Wertheimer, A.I. The economics of polypharmacology: Fixed dose combinations and drug cocktails. Curr. Med. Chem., 2013, 20, in press.

[95] Bolognesi, M.L. Polypharmacology in a single drug: multitarget drugs. Curr. Med. Chem., 2013, 20, in press.

[96] Liu, X.; Zhu, F.; Ma, X.H.; Shi, Z.; Yang, S.Y.; Wei, Y.Q.; Chen, Y.Z. Predicting targeted polypharmacology for drug repositioning and multi-target drug discovery. Curr. Med. Chem., 2013, 20, in press.

[97] Geldenhuys, W.J.; Van der Schyf, C.J. Rationally designed multi-targeted agents against neurodegenerative diseases. Curr. Med. Chem., 2013, 20, in press.

[98] Chen, X.; Decker, M. Multi-target compounds acting in the central nervous system designed from natural products. Curr. Med. Chem., 2013, 20, in press.

[99] Russo, P.; Frustaci, A.; Fini, M.; Cesario, A. Multitarget drugs of plants origin acting on Alzheimer's disease. Curr. Med. Chem., 2013, 20, in press.

[100] Chen, Z.; Han, L.; Xu, M.; Xu, Y.; Qian, X. Rationally designed multitarget anticancer agents. Curr. Med. Chem., 2013, 20, in press.

[101] Mbugua Njogu, P.; Chibale, K. Recent developments in rationally designed multitarget antiprotozoan agents. Curr. Med. Chem., 2013, 20, in press.

[102] Zhan, P.; Liu, X. Rationally designed multitarget anti-HIV agents. Curr. Med. Chem., 2013, 20, in press. 
[103] Bisi, A.; Gobbi, S.; Belluti, F.; Rampa, A. Design of multifunctional compounds for cardiovascular disease: from natural scaffolds to "classical" multitarget approach. Curr. Med. Chem., 2013, 20, in press.

[104] Hwang, S.H.; Wecksler, A.T.; Wagner, K.; Hammock, B.D. Rationally designed multitarget agents against inflammation and pain. Curr. Med. Chem., 2013, 20, in press.

[105] O’Connor, K.A.; Roth, B.L. Finding new tricks for old drugs: an efficient route for public-sector drug discovery. Nat. Rev. Drug Discov., 2005, 4, 1005-1014.

[106] Ashburn, T.T.; Thor, K.B. Drug repositioning: identifying and developing new uses for existing drugs. Nat. Rev. Drug Discov., 2004, 3, 673-683.

[107] Oprea, T.I.; Bauman, J.E.; Bologa, C.G.; Buranda, T.; Chiagev, A.; Edwards, B.S.; Jarvik, J.W.; Gresham, H.D.; Haynes, M.K.; Hjelle, B.; Hromas, R.; Hudson, L.; Mackenzie, D.A.; Muller, C.Y.; Reed, J.C.; Simons, P.C.; Smagley, Y.; Strouse, J.; Suriladze, Z.; Thompson, T.; Ursu, O.; Waller, A.; WandingerNess, A.; Winter, S.S.; Wu, Y.; Young, S.M.; Larson, R.S.; William, C.; Sklar, L.A. Drug repurposing from an academic perspective. Drug Discov. Today, 2011, 8, 61-69.

[108] Doan, T.L.; Pollastri, M.; Walters, M.A.; Georg, G.I.; Macor, J.E. The future of drug repositioning: old drugs, new opportunities. Annu. Rep. Med. Chem., 2011, $8,61-69$.

[109] Aubé, J. Drug repurposing and the medicinal chemist. ACS Med. Chem. Lett., 2012, 3, 442-444. 
[110] Blum, L.C.; Reymond, J.L. 970 Million druglike small molecules for virtual screening in the chemical universe database GDB-13. J. Am. Chem. Soc., 2009, $131,8732-8733$.

[111] Ekins, S.; Mestres, J.; Testa, B. In silico pharmacology for drug discovery: methods for virtual ligand screening and profiling Br. J. Pharmacol., 2007, 152, $9-20$.

[112] Nonell-Canals, A.; Mestres, J. In silico target profiling of one billion molecules. Mol. Inf., 2011, 30, 405-409.

[113] Yang, L; Agarwal, P. Systematic drug repositioning based on clinical sideeffects. PLoS ONE, 2011, 6, e28025.

[114] Durrant, J.D.; Amaro, R.E.; Xie, L.; Urbaniak, M.D.; Ferguson, M.A.J.; Haapalainen, A.; Chen, Z.; Di Guilmi, A.M.; Wunder, F.; Bourne, P.E.; McCammon, J.A. A multidimensional strategy to detect polyphamacological targets in the absence of structural and sequence homology. PLoS Comp. Biol., 2010, 6, e1000648.

[115] Duran-Frigola, M.; Aloy, P. Recycling side-effects into clinical makers for drug repositioning. Genome Medicine, 2012, 4, 3.

[116] Boguski, K.S.; Mandl, K.D.; Sukhadme, V.P. Drug discovery. Repurposing with difference. Science, 2009, 324, 1394-1395.

[117] Wermuth, C.G. Selective optimization of side activities: another way for drug discovery. J. Med. Chem., 2004, 47, 1303-1314.

[118] Wermuth, C.G. The "SOSA" approach: an alternative to high-throughput screening. Med. Chem. Res., 2001, 10, 431-439. 
[119] Wermuth, C.G. Multitargeted drugs: the end of the "one-target-one-disease" philosophy? Drug Discov. Today, 2004, 9, 826-827.

[120] Zimmermann, G.R.; Lehar, J.; Keith, T.K. Multi-target therapeutics: when the whole is greater than the sum of the parts. Drug Discov. Today, 2007, 12, 34-42.

[121] Cole, G.M.; Frautschy, S.A. Commentary on "cytoskeletal modulators and pleiotropic strategies for Alzheimer drug discovery." Pleiotropic approaches to Alzheimer's and other diseases of aging. Alzheimer's and Dementia, 2006, 2, 284-286

[122] Podolsky, S.H.; Greene, J.A. Combination drugs-hype, harm and hope. N. Engl. J. Med., 2011, 365, 488-491.

[123] Volpe, M.; Chin, D.; Paneni, F. The challenge of polypharmacy in cardiovascular medicine. Fundament. Clin. Pharmacol., 2010, 24, 9-17.

[124] Zhou, H.; Tong, Z.; McLeod, J.F. "Cocktail” approaches and strategies in drug development: valuable tool or flawed science? J. Clin. Pharmacol., 2004, 44, 120-134.

[125] Radhakrishnan, M.L.; Tidor, B. J. Optimal drug cocktail design: Methods for targeting molecular ensembles and insights from theoretical model systems. $J$. Chem. Inf. Model., 2008, 48, 1055-1073.

[126] Borisy, A.A.; Elliott, P.J.; Hurst, N.W.; Lee, M.S.; Lehár, J.; Price, E.R.; Serbedzija, G.; Zimmermann, G.R.; Foley, M.A.; Stockwell, B.R.; Keith, C.T. Systematic discovery of multipotent therapeutics. Proc. Natl. Sci. U.S.A., 2003, $100,7977-7982$

[127] Araujo, R.P.; Petricoin, E.F.; Liotta, L.A. A mathematical model of combination therapy using the EGFR signalling network. Biosystems, 2005, 80, 57-69. 
[128] Lehár, J.; Krueger, A.S.; Avery, W.; Heilbut, A.M.; Johansen, L.M.; Price, E.R.; Rickles, R.J.; Short III, G.F.; Staunton, J.E.; Jin, X.; Lee, M.S.; Zimmermann, G.R.; Borisy, A.A. Synergistic drug combinations tend to improve therapeutically relevant selectivity. Nat. Biotechnol., 2009, 27, 659-666.

[129] Bangalore, S.; Kamalakkannan, G.; Parkar, S.; Messerli, F.H. Fixed-dose combinations improve medication compliance: a meta-analysis. Am. J. Med., 2007, 120, 713-719.

[130] Cavalli, A.; Bolognesi, M.L. Minarini, A, ; Rosini, M.; Tumiatti, V.; Recanatini, M.; Melchiorre, C. Multi-target-directed ligands to combat neurodegenerative diseases. J. Med. Chem., 2008, 51, 347-372.

[131] García-Donaire, J.A.; Ruilope, L.M. "Multiple action fixed combination. Present or future?". Fundament. Clin. Pharmacol., 2010, 24, 37-42.

[132] Guidance for industry-codevelopment of two or more unmarketed investigational drugs for use in combination, Rockville, M.D. Food and Drug Administration.

2010 (draft). (http:/www.fda.gov/downloads/Drugs/Guidance/UMC236669.pdf).

[133] Weinreb, O.; Amit, T.; Bar-Am, O.; Youdim, M.B.H. Ladostigil: A novel multimodal neuroprotective drug with cholinesterase and brain-selective monoamine oxidase inhibitory activities for Alzheimer's disease treatment. Curr. Drug Targets, 2012, 13, 483-494.

[134] Morphy, R.; Rankovic, Z. The physicochemical challenges of designing multiple ligands. J. Med. Chem., 2006, 49, 4961-4970.

[135] Morphy, R.; Rankovic, Z. Designing multiple-ligands-medicinal chemistry strategies and challenges. Curr. Pharm. Des., 2009, 15, 587-600. 
[136] Morphy, R.; Rankovic, Z. Fragments, network biology and designing multiple ligands. Drug Discov. Today, 2007, 12, 156-160.

[137] Morphy, R.; Kay, C.; Rankovic, Z. From magic bullets to designed multiple ligands. Drug Discov. Today, 2004, 9, 641-651.

[138] Hann, M.M.; Leach, A.R.; Harper, G. Molecular complexity and its impact on the probability of finding leads for drug discovery. J. Chem. Inf. Comput. Sci., 2001, $41,856-864$.

[139] Hopkins, A.L.; Mason, J.S.; Overington, J.P. Can we rationally design promiscuous drugs? Curr. Opin. Struct. Biol., 2006, 16, 127-136.

[140] Hugging, D.J.; Sherman, W.; Tidor, B. Rational approaches to improving selectivity in drug design. J. Med. Chem., 2012, 55, 1424-1444. 